\title{
TÉCNICA DE COMPOSTAGEM APLICADA A LODO FLOTADO DE UM ABATEDOURO DE FRANGOS
}

Alexandre Couto Rodrigues ${ }^{1}$, Rúbia Carla Passaglia ${ }^{2}$, Andriele Focking ${ }^{3}$, Aline Ferrão Custódio Passini ${ }^{4}$, Claudia Regina Pazini ${ }^{5}$

1 Professor do Departamento de Engenharia e Tecnologia Ambiental, Universidade

Federal de Santa Maria (UFSM), campus de Frederico Westphalen, Brasil.

(coutoalexandre@yahoo.com.br)

2 Pós-graduanda do curso de especialização em Agricultura Familiar e

Desenvolvimento Sustentável, Universidade Estadual do Rio Grande do Sul

(UERGS), unidade de Erechim, Brasil.

3 Mestranda no Programa de Pós-Graduação em Bioenergia, Universidade Estadual do Oeste do Paraná (UNIOESTE), campus de Toledo, Brasil.

4 Professora do Departamento de Engenharia e Tecnologia Ambiental, Universidade

Federal de Santa Maria (UFSM), campus de Frederico Westphalen, Brasil.

5 Mestranda no Programa de Pós-Graduação em Engenharia Química, Universidade Estadual do Oeste do Paraná (UNIOESTE), campus de Toledo, Brasil.

\section{Recebido em: 03/10/2016 - Aprovado em: 21/11/2016 - Publicado em: 05/12/2016 DOI: 10.18677/EnciBio 2016B 093}

O lodo flotado do abatedouro em questão é oriundo do tratamento físico-químico dos efluentes industriais, o qual possui um sistema de microbolhas de ar, e que com a adição de um coagulante e um polímero, fazem com que as partículas sólidas flotem, e sejam removidas mecanicamente por pás raspadoras e depositadas em um tanque anexo. O efluente da indústria é composto por resíduos de sangue, vísceras, gorduras, penas, restos de carne, ossos e água de higienização. Objetivou-se com este trabalho avaliar a viabilidade da aplicação da técnica de compostagem na estabilização de lodo flotado oriundo de abatedouro de frangos e analisar o potencial nutricional do composto formado. Para isso, utilizou-se como material orgânico o lodo flotado do abatedouro, rico em nitrogênio, serragem de madeira e palha de milho, ambas ricas em carbono. Em um dos tratamentos, aplicou-se cinzas, provenientes das caldeiras da indústria, a fim de comparar a variação do $\mathrm{pH}$. Concluiu-se que a técnica da compostagem se apresenta como uma alternativa ambientalmente adequada para estabilização do lodo, pois através dessa, o lodo resultou em um composto orgânico que poderá ser utilizado na agricultura como adubo orgânico ou condicionador de solo. Todavia, recomenda-se efetuar uma análise química do lodo flotado para obter conhecimento de suas características e poder estabelecer uma correta relação $\mathrm{C} / \mathrm{N}$ na confecção das leiras, garantindo maior eficiência no processo e alcançar um fertilizante de melhor qualidade.

PALAVRAS-CHAVE: adubo orgânico, avaliação nutricional, valorização da matéria orgânica 


\title{
TECHNIQUE APPLIED TO COMPOSTING SLUDGE FLOAT ORIGINATED OF WASTEWATER TREATMENT OF A CHICKEN SLAUGHTERHOUSE
}

\begin{abstract}
The float of slaughterhouse sludge in question arises from the physic-chemical treatment of industrial effluents, which has a system of air microbubbles and with the addition of a coagulant and a polymer, make solid particles from the effluent be floated, and are mechanically removed by scraping blades and deposited in an annex tank. The industry effluent is composed of residues of blood, viscera, fat, feathers, meat scraps, bones and sanitizing water. The objective of this study was to evaluate the feasibility of applying the composting technique in sludge stabilization float come from poultry slaughterhouse and analyze the nutritional potential of the compound formed. For this was used as the organic material float sludge slaughterhouse, rich in nitrogen, sawdust and corn stover, both rich in carbon. In one treatment, applied ashes from the industrial boilers, in order to compare the change in $\mathrm{pH}$. It was concluded that the composting technique presents itself as an environmentally sound alternative for sludge stabilization, because through this, the sludge resulted in an organic compound that can be used in agriculture as organic fertilizer or soil conditioner. However, it is recommended to perform a chemical analysis of the float sludge to obtain knowledge of their characteristics and to establish a correct $\mathrm{C} / \mathrm{N}$ ratio in the pile building, ensuring greater efficiency in the process and achieve a better quality fertilizer.
\end{abstract}

KEYWORDS: nutritional assessment, organic fertilizer, recovery of organic matter

\section{INTRODUÇÃO}

O lodo flotado do abatedouro em questão é oriundo do tratamento físicoquímico dos efluentes industriais, o qual possui um sistema de microbolhas de ar, e que com a adição de um coagulante e um polímero, fazem com que as partículas sólidas do efluente flotem, e sejam removidas mecanicamente por pás raspadoras e depositadas em um tanque anexo ao flotador (BERNARDI, 2011).

Segundo CASTRO et al., (2011), os sistemas de tratamento de águas residuárias industriais têm a finalidade de garantir a qualidade do efluente e atender a legislação, antes de lançá-los nos corpos d'água.

O efluente da indústria é composto por resíduos de sangue, vísceras, gorduras, penas, restos de carne, ossos e água de higienização. Portanto, quando disposto incorretamente no solo ou em corpos de água, esse lodo pode se tornar um passivo ambiental, afetando direta ou indiretamente os seres humanos.

Uma alternativa para tratamento de resíduos orgânicos que vem sendo muito utilizada é a compostagem. Para GOMES (2011), a compostagem é um processo de valorização da matéria orgânica, que consiste na decomposição de resíduos orgânicos por ação de microrganismos na presença de oxigênio, produzindo um composto estável que pode ser utilizado como fertilizante.

O desempenho do processo de compostagem sofre influência de diversos fatores, como pH, aeração, umidade, temperatura, microrganismos, relação carbono/nitrogênio (C/N), tamanho das partículas. Para WARTCHOW et al., (2011), os fatores que mais influenciam são a aeração, os nutrientes e a umidade, e, não menos importante, a temperatura que é responsável pela rapidez no processo de 
biodegradação e na supressão de patógenos, porém, ela é considerada um resultado da atividade microbiana através do processo de fermentação.

De acordo com BERNARDI (2011), o processo de compostagem deve passar por algumas fases para que se tenha um composto de boa qualidade, sendo a primeira denominada de fase mesófila onde a matéria orgânica parte da temperatura ambiente subindo para a fase termófila - segunda fase, na qual a temperatura atinge seu máximo valor, em torno de $60 \stackrel{\circ}{\circ}$, ocasionando a destruição dos organismos patogênicos; a temperatura retorna a baixar voltando para a fase mesófila - terceira fase, e após vem a fase de maturação ou criófila - quarta fase, em que a temperatura decresce até atingir a temperatura ambiente, caracterizando a cura do composto. Esta última é a fase mais longa do processo, sendo que o processo todo tem uma duração de aproximadamente 120 dias.

Assim, objetivou-se com este trabalho avaliar a viabilidade da aplicação da técnica de compostagem na estabilização de lodo flotado oriundo de abatedouro de frangos e analisar o potencial nutricional do composto formado.

\section{MATERIAIS E MÉTODOS}

O trabalho foi realizado no município de Frederico Westphalen, localizado no noroeste do estado do Rio Grande do Sul, nas coordenadas latitude 27은 $46^{\prime \prime}$ e longitude 5325’37”, a uma altitude aproximada de 477 metros do nível do mar.

A área escolhida para realizar o experimento era em declive, e por isso teve que ser nivelada para evitar o desmoronamento das leiras. A mesma tinha aproximadamente $20 \mathrm{~m}^{2}$ e foi cercada, com o intuito de evitar a possível invasão de animais. Essa área foi coberta com lona plástica preta para a impermeabilização do solo caso ocorresse a formação de lixiviado. Em volta da área, também foram feitas canaletas para que a água da chuva não escorresse por cima da lona, o que poderia causar o arraste das leiras.

Para a confecção das leiras utilizou-se como material orgânico o lodo flotado do abatedouro, rico em nitrogênio, alternado com camadas de serragem de madeira e palha de milho, ambas ricas em carbono. Aplicou-se também, em uma das leiras, as cinzas provenientes das caldeiras da indústria, a fim de analisar a variância do $\mathrm{pH}$. As nove leiras foram preparadas entre os dias 28 e 29 de março de 2012 (Figura 1), divididas em três tratamentos com três repetições cada: a testemunha (T1) composta por camadas intercaladas de $15 \mathrm{~cm}$ de serragem e $5 \mathrm{~cm}$ de lodo; 0 tratamento 2 (T2) - composto por $10 \mathrm{~cm}$ de serragem, $5 \mathrm{~cm}$ de cinzas e $5 \mathrm{~cm}$ de lodo; o tratamento 3 (T3) - $10 \mathrm{~cm}$ de serragem, $5 \mathrm{~cm}$ de palha de milho e $5 \mathrm{~cm}$ de lodo. 


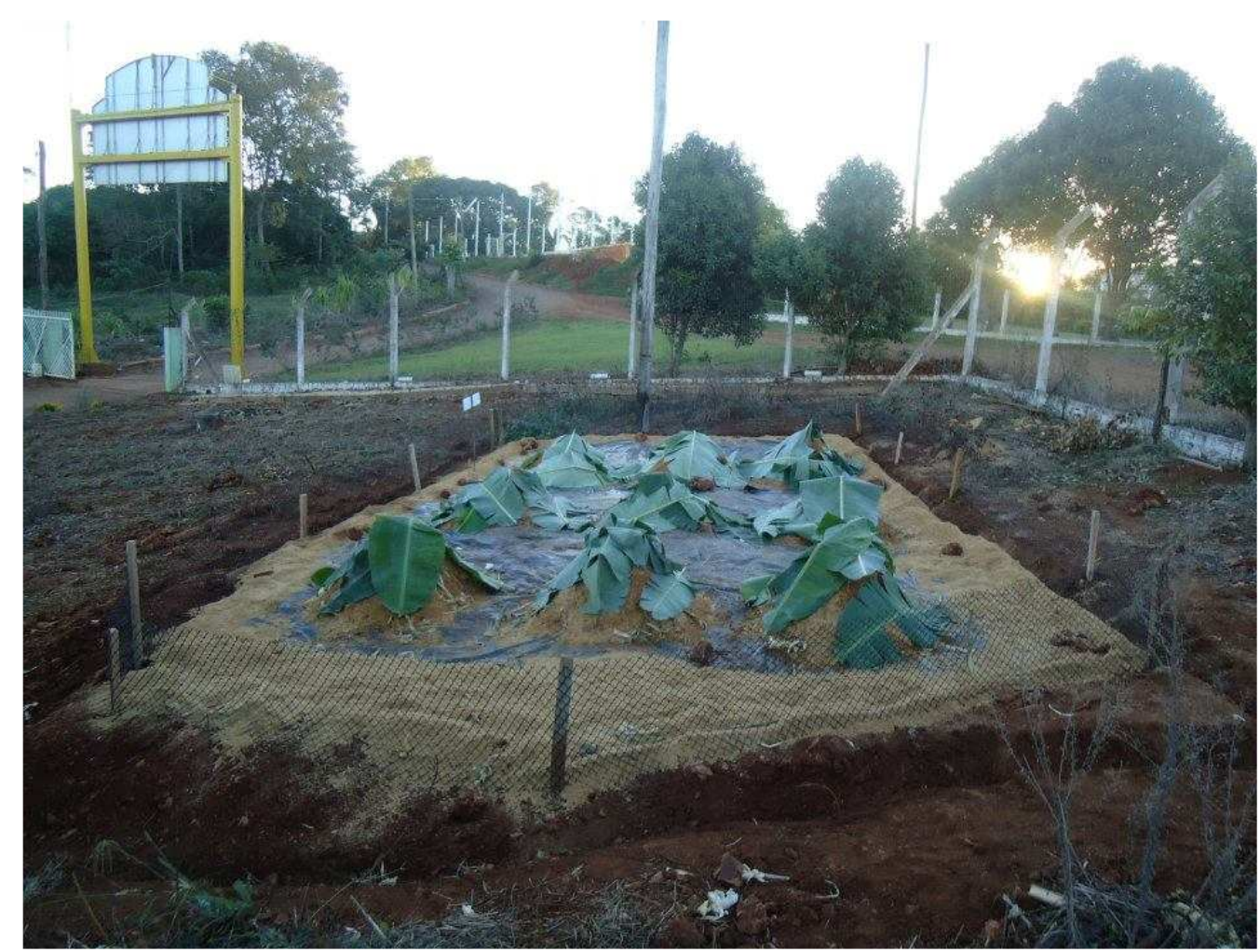

FIGURA 1: Nove leiras confeccionadas

Cada leira possuía uma base de $1 \mathrm{~m}^{2}$ e altura média de $75 \mathrm{~cm}$. Quando prontas, foram umedecidas e cobertas com folhas de bananeira a fim de evitar a perda de umidade e a lixiviação nos dias de chuva. No dia 02 de abril de 2012, percebeu-se a necessidade de agrupar as leiras de mesmo tratamento, pois as suas alturas não atingiram a medida ideal, que seria de 1,5 metros, garantindo assim, uma maior eficiência no processo de estabilização da matéria orgânica.

Para garantir umidade próxima a $50 \%$, as leiras foram umedecidas com água regularmente. $O$ revolvimento era feito a cada 15 dias e a temperatura era medida semanalmente, obtendo-se, assim, um melhor controle das fases do processo. A temperatura era medida em quatro pontos diferentes da leira, como segue na Tabela 1:

TABELA 1 - Pontos de medição da temperatura nas leiras

\begin{tabular}{ccc}
\hline PONTO & ALTURA $(\mathbf{c m})$ & PROFUNDIDADE $(\mathbf{c m})$ \\
\hline $\mathbf{1}$ & 20 & 20 \\
$\mathbf{2}$ & 20 & 50 \\
$\mathbf{3}$ & 40 & 20 \\
$\mathbf{4}$ & 60 & 20 \\
\hline
\end{tabular}

Avaliou-se também a ausência, presença ou presença intensa de: odor, moscas, larvas, formigas, formação de lixiviado, umidade e mudanças de coloração na leira. Para avaliar a maturação realizou-se o teste do sal amoníaco, segundo OLIVEIRA et al., (2005). Para isso, utilizou-se um copo de vidro transparente, onde foram misturados aproximadamente 50 gramas de composto com uma colher de café de sal amoníaco e água até completar o volume do copo. O teste foi repetido para os três tratamentos. 
Após o composto ter atingido a maturação, com o auxílio de um trado, coletaram-se amostras de 500 gramas de composto de cada tratamento. Essas amostras foram encaminhadas para o Laboratório de Química da Faculdade de Agronomia "Eliseu Maciel" do Departamento de Solos da Universidade Federal de Pelotas, onde foram feitas análises biológicas de coliformes totais e Escherichia coli, e as análises químicas descritas na Tabela 2:

TABELA 2 - Atributos químicos analisados e respectiva metodologia utilizada

DETERMINACÕES

Carbono orgânico $\mathbf{g} / \mathbf{k g}$

Nitrogênio total $\mathbf{g} / \mathbf{k g}$

Fósforo total $\mathbf{g} / \mathbf{k g}$

Potássio total $\mathbf{g} / \mathbf{k g}$

Cobre total $\mathrm{mg} / \mathrm{kg}$

Zinco total $\mathrm{mg} / \mathrm{kg}$ METODOLOGIA APLICADA

Combustão úmida - Walkey Black

Digestão sulfúrica - Kjeldahl

Digestão sulfúrica - Espectometria AM

Digestão sulfúrica - Espectometria AA

Digestão nitro-perclórica - Espectometria $A A$

Digestão nitro-perclórica - Espectometria AA

\section{RESULTADOS E DISCUSSÃO}

Segundo SILVA (2003), a rapidez com que se atinge o estado de maturação do composto depende de vários fatores como a concentração de nutrientes, $\mathrm{pH}$, aeração e revolvimento da leira, teor de umidade e tamanho das partículas.

Ao final do processo de compostagem, CERRI et al., (2008) dizem que a maturação do composto é atingida quando este apresentar coloração escura, cheiro de bolor e consistência amanteigada, quando molhado e esfregado entre as mãos. Essas características foram observadas depois de transcorridas 15 semanas do processo de compostagem do lodo. A literatura cita que a duração do processo de compostagem dura em média de 90 a 120 dias, dependendo do tipo de material utilizado. Sendo assim, pode-se dizer que o composto obtido atingiu a maturação dentro do período recomendado.

VALENTE et al. (2009), afirmam que a temperatura é frequentemente considerada o mais importante indicador da eficiência do processo de compostagem, visto que está relacionada à atividade metabólica dos microrganismos. Considerando as medições de temperatura realizadas durante o processo foi possível verificar a ocorrência das quatro fases da compostagem citadas por BERNARDI (2011): mesófila, termófila, mesófila 2 e fase de maturação ou criófila. As temperaturas apresentadas foram semelhantes nos três tratamentos, desde 0 início até o final do processo, quando a temperatura das leiras atingiu a temperatura próxima a ambiente. Tais afirmações são ratificadas pelo Gráfico de Temperatura (Figura 2). 


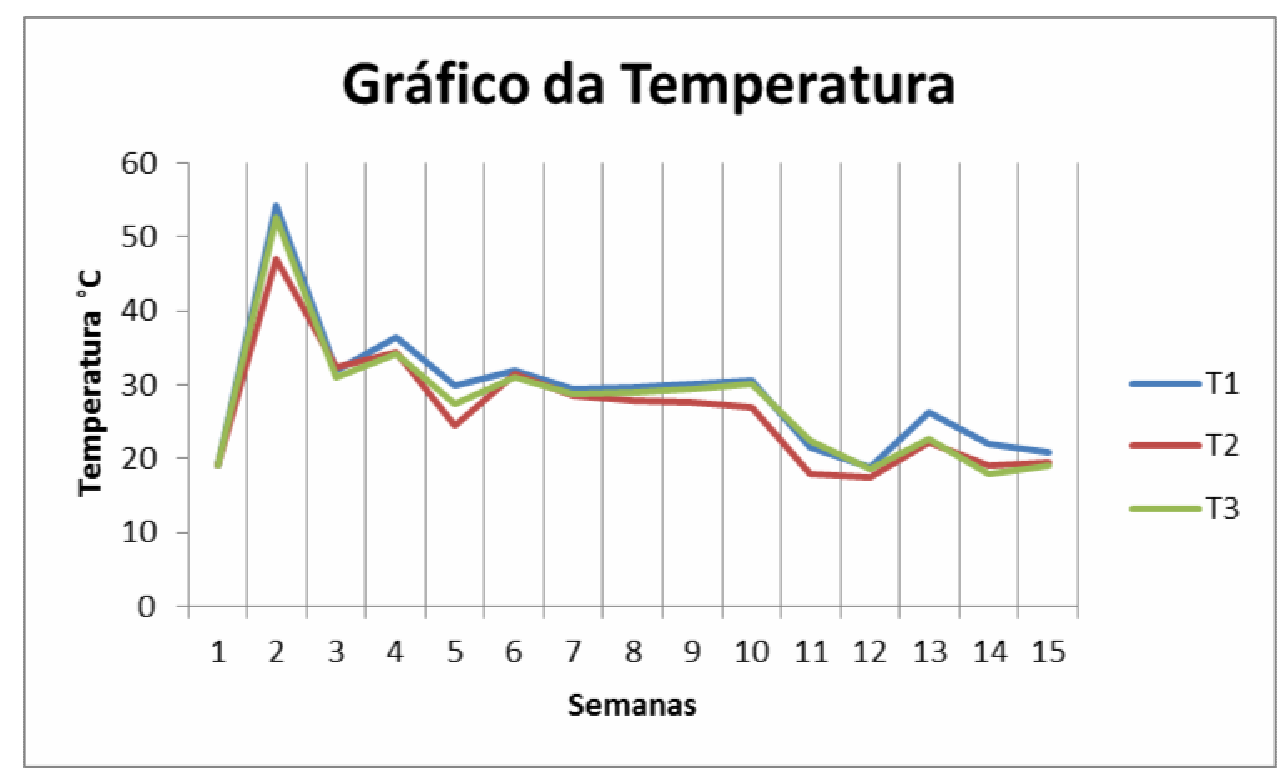

FIGURA 2: Gráfico da temperatura

O processo de compostagem deve garantir através da fase termófila, a eliminação de patógenos que podem estar presentes no material de origem, uma vez que a presença/ausência destes influenciará na evolução e qualidade do processo (HECK et al., 2013). Portanto, quanto maior a temperatura alcançada durante o processo de estabilização, menores as chances de o composto final conter microrganismos patógenos. Trabalhos como o de PAIVA et al. (2012) alcançaram temperatura de até $82{ }^{\circ} \mathrm{C}$ avaliando a eficiência do processo e a qualidade microbiológica do composto oriundo de carcaça de frango, bagaço de cana-deaçúcar, palha de café e cama de frango.

A temperatura máxima atingida foi constatada no $T 1$, logo na segunda semana, com valor aproximado de $55^{\circ} \mathrm{C}$. Temperaturas semelhantes foram obtidas no trabalho de ABREU et al. (2011), onde foi avaliada a atuação da casca de arroz e da palhada de soja como substrato para compostagem de carcaça de frangos de corte.

Dentre as variáveis observadas, na primeira semana foi constatada a presença intensa de larvas e moscas em todas as leiras, além de odor intenso. Contudo, desapareceram logo nos dias seguintes, devido, possivelmente, ao aumento de temperatura que pode ter ocasionado a eliminação. Também foi possível observar formigas e aranhas, durante um período entre a terceira e a oitava semana do processo, as quais auxiliam na decomposição de fibras vegetais e animais, transformando substâncias orgânicas complexas em substâncias mais simples.

Apesar das leiras terem sido regularmente irrigadas, não verificou-se a formação de lixiviado durante o processo de compostagem. Já a coloração das leiras escureceu ao longo do processo de estabilização da matéria orgânica. Observações próximas a estas também foram realizadas no trabalho de GRAEPIN et al. (2014) o qual relata a aplicação da técnica de compostagem como forma de disposição do lodo gerado no tratamento de efluentes de um abatedouro de frangos. As análises químicas foram realizadas em triplicata e calculadas as respectivas médias, conforme Tabela 3. 
TABELA 3 - Média dos parâmetros químicos para os três tratamentos

\begin{tabular}{|c|c|c|c|c|c|c|c|c|c}
\hline $\begin{array}{c}\text { Trata- } \\
\text { mento }\end{array}$ & $\begin{array}{c}\mathbf{C} \\
\mathbf{( g / K g})\end{array}$ & $\begin{array}{c}\mathbf{N} \\
\mathbf{( g / k g})\end{array}$ & $\mathbf{C} / \mathbf{N}$ & $\mathbf{p H}$ & $\begin{array}{c}\mathbf{P} \\
\left(\mathbf{m g} . \mathbf{K g}^{-1}\right)\end{array}$ & $\begin{array}{c}\mathbf{K} \\
\left(\mathbf{m g} . \mathbf{K g}^{-1}\right)\end{array}$ & $\begin{array}{c}\mathbf{M O} \\
(\mathbf{\%})\end{array}$ & $\begin{array}{c}\mathbf{Z n} \\
(\mathbf{m g} / \mathbf{L})\end{array}$ & $\begin{array}{c}\mathbf{C u} \\
(\mathbf{m g} / \mathbf{L})\end{array}$ \\
\hline T3 & 550,87 & 14,59 & 38 & 6,4 & 76 & 161,2 & 22,3 & 6,326 & 0,419 \\
T2 & 298,97 & 7,47 & 40 & 7.3 & 74 & 394,6 & 22,3 & 4,369 & 0,472 \\
T1 & 554,14 & 12,33 & 45 & 8,2 & 76 & 618,6 & 22,3 & 2,206 & 0,444 \\
\hline
\end{tabular}

Com relação a matéria orgânica, sua decomposição durante o processo ocorre com alteração contínua, conforme a variação de temperatura, $\mathrm{pH}$ e a disponibilidade de alimento para os microrganismos (SILVA, 2003), estabelecendo uma relação aproximada entre a temperatura do processo e o grau de decomposição. A literatura traz o valor de $934,5 \mathrm{~g} / \mathrm{kg}$ de M.O. presente na serragem de madeira, ou seja, um valor considerado alto e que pode ter influenciado no resultado percentual de M.O. do composto final.

Os processos de estabilização de M.O. levam à mineralização de parte do material lábil e à humificação de outra parcela, logo, existe uma diminuição no teor de M.O., uma vez que parte do carbono inicial se perde para atmosfera em forma de $\mathrm{CO}_{2}$, como consequência da respiração dos microrganismos (DORES-SILVA et al., 2013). A digestão da matéria orgânica por organismos e microrganismos diversos resulta na liberação de nutrientes como nitrogênio, fósforo e potássio, que anteriormente encontravam-se imobilizados.

A quantidade de fósforo analisada no composto final foi próxima nos três tratamentos, porém as análises de potássio apresentaram diferença significativa entre os três tratamentos. Percebe-se que no tratamento em que se utilizou serragem e palha de milho (T3) foi o que apresentou menor valor de potássio, em contrapartida, foi o que apresentou o maior valor para zinco.

Comparando as análises de fósforo e potássio com o trabalho de COSTA et al. (2008), o composto apresentou valores inferiores desses micronutrientes. Acredita-se que a alta relação $\mathrm{C} / \mathrm{N}$ da serragem tenha influenciado na estabilização do composto e como consequência, na liberação dos nutrientes. Entretanto, SUNADA et al. (2015), verificaram redução dos nutrientes ao longo dos 147 dias do processo de compostagem com resíduo sólido de abate de aves e casca de arroz, indicando que quanto maior o tempo do processo, menor a quantidade de nutrientes presentes no composto final.

Trabalho de SILVA (2003) realizado com co-compostagem de resíduos orgânicos também mostra valores muito elevados de cálcio, magnésio, potássio e fósforo para resíduo avícola. A mesma autora também identificou a presença de metais como zinco e cobre no composto final.

Quanto à relação $\mathrm{C} / \mathrm{N}$, os resultados apresentaram valores bastante elevados, ultrapassando o valor máximo recomendado pela Legislação Brasileira que é 18:1 com tolerância de até 21:1 (IN no 25, 2009). Isso porque, segundo OLIVEIRA et al., (2005), a serragem apresenta uma relação $\mathrm{C} / \mathrm{N}$ alta, em torno de 865:1, enquanto que a relação $\mathrm{C} / \mathrm{N}$ do lodo flotado pode variar de 2 a 9, segundo BERNARDI (2011). A relação $\mathrm{C} / \mathrm{N}$ da palha de milho é de 112:1, e também é considerada alta (OLIVEIRA et al., 2005). Contudo, a relação $\mathrm{C} / \mathrm{N}$ da palha de milho é menor do que a relação $\mathrm{C} / \mathrm{N}$ da serragem, justificando o fato da relação $\mathrm{C} / \mathrm{N}$ do $\mathrm{T} 3$ ter sido menor que do T1 e T2. Apesar disso, as análises de carbono e nitrogênio do T2 foram menores que no T1 e T3, possivelmente pelo fato da aplicação das cinzas, que 
podem ter influenciado na variação do $\mathrm{pH}$ ao longo do processo, pois com o $\mathrm{pH}$ ótimo para o desenvolvimento dos microrganismos, a degradação do carbono e nitrogênio ocorre mais rapidamente.

Em trabalho realizado por LEITÃO et al. (2011) concluíram que a relação $\mathrm{C} / \mathrm{N}$ indica o grau de decomposição do composto e que quanto mais alta a relação $\mathrm{C} / \mathrm{N}$ do material de origem maior será o tempo de degradação do mesmo. SUNADA et al. (2015) indicaram relação $\mathrm{C} / \mathrm{N}$ para resíduo sólido de abatedouro avícola com valor médio de 3,90. Para SANTOS (2007) o intervalo ótimo para relação $\mathrm{C} / \mathrm{N}$ do composto final deve estar compreendido entre 25:1 e 30:1.

Para SILVA (2003), o pH não é considerado um fator crítico visto que ocorre um fenômeno de "autorregulação" resultante da atividade microbiana. O mesmo autor também comenta que no processo de compostagem, deve-se atender a gama de $\mathrm{pH}$ mais favorável para a maioria dos microrganismos participantes, sendo que 0 valor de $\mathrm{pH}$ ótimo para bactérias varia entre 6,0 e 7,5, e para fungos entre 5,5 e 8,0. Para SANTOS (2007) o valor ótimo de pH está compreendido entre 5 e 8, intervalo que compreende o $\mathrm{pH}$ dos três tratamentos analisados.

As cinzas apresentam em sua composição, quantidades razoáveis de macro e micronutrientes, têm potencial para serem utilizadas como adubo e características de corretivo de acidez do solo. A presença de $\mathrm{K}_{2} \mathrm{O}$ e de $\mathrm{CaO}$ promovem ao material ação alcalina o que pode contribuir com a correção da acidez dos solos (RIBEIRO et al., 2015). O tratamento T2 o qual teve aplicação das cinzas, apresentou um pH básico, muito próximo de $7 \mathrm{e}$, aliado as altas temperaturas atingidas durante 0 processo, pode ter favorecido a perda de nitrogênio por volatilização da amônia, e por isso apresentou menor quantidade de nitrogênio nas análises realizadas.

Os resultados das análises microbiológicas do composto final estão apresentas na Tabela 4. A presença ou ausência de bactérias no processo de compostagem está diretamente relacionada à fase termofílica da leira. Sendo assim, o sucesso da eliminação de microrganismos patogênicos depende das altas temperaturas que leira deve atingir, além do tempo de exposição e da uniformidade da temperatura a que o material está submetido (ARTHURSON, 2008).

TABELA 4: Laudo de análise microbiológica

\begin{tabular}{|c|c|c}
\hline TRATAMENTO & $\begin{array}{c}\text { COLIFORMES } \\
\text { TOTAIS/NMP.100ml }\end{array}$ & E. coli/ NMP.100ml \\
& 3,5405 & 0,6333 \\
T1 & 2,0986 & 7,1000 \\
T2 & 2,0495 & 1,4666 \\
\hline
\end{tabular}

A Instrução Normativa № 27 de 05 de junho de 2006, do Ministério da Agricultura, Pecuária e Abastecimento, em seu Anexo $V$ estabelece como limite máximo de coliformes termotolerantes o valor de $1.000 \mathrm{NMP} / \mathrm{g}$ de MS. Levando em consideração os valores de $E$. coli é possível conferir que os resultados estão dentro do estabelecido pela Instrução Normativa.

\section{CONCLUSÃO}

A técnica da compostagem se apresenta como uma alternativa ambientalmente adequada para estabilização desse lodo, resultando em adubo orgânico ou condicionador de solo que pode ser utilizado na agricultura. 
Todavia, recomenda-se efetuar uma análise química do lodo flotado para obter conhecimento de suas características e poder estabelecer uma correta relação $\mathrm{C} / \mathrm{N}$ na confecção das leiras, garantindo maior eficiência no processo e alcançar um fertilizante de melhor qualidade e biodisponibilidade de nutrientes.

Recomenda-se também a busca por alternativas de resíduos de carbono, pois percebeu-se que a serragem apresenta uma relação $\mathrm{C} / \mathrm{N}$ muito alta e pode ter influenciado na estabilização do composto e consequentemente na liberação dos nutrientes.

Observou-se que a utilização de cinzas no T2 pode ter influenciado na variação do $\mathrm{pH}$ durante o processo, pois a quantidade de nitrogênio e carbono presente no composto final do T2 foi menor que nos outros tratamentos.

\section{REFERÊNCIAS}

ABREU, P. G. de; PAIVA, D. P-de-; ABREU, V. M. N.; COlDEBELlA, A.; CESTONARO, T. Casca de arroz e palhada de soja na compostagem de carcaças de frangos de corte. In: Revista Acta Scientiarum, Maringá, vol. 33, n. 1, p. 51-57, 2011. DOI: 10.4025/actascianimsci.v33i1.10824

ARTHURSON, V. Proper sanitization os sewage sludge: a critical issue for a sustainable society. In: Revista Applied and Environmental Microbiology, v. 74, n. 17, p. 5267-5275, set. 2008, Washington DC.

BERNARDI, F. H. Uso do proceso de compostagem no aproveitamento de residuos de incubatório e outros de origen agroindustrial. Programa de PósGraduação em Engenharia Agrícola, Centro de Ciencias Exatas e Tecnológicas, Universidade Estadual do Oeste do Paraná, Cascavel, PR, 2011.

BRASIL. Ministério da Agricultura, Pecuária e Abastecimento. Instrução Normativa no 25 , de 23 de julho de 2009. Aprova as normas sobre as especificações e as garantia, as tolerâncias, o registro, a embalagem e a rotulagem dos fertilizantes orgânicos simples, mistos, compostos, organominerais e biofertilizantes destinados à agricultura. Diário Oficial da União, 28 de jul. 2009, Seção 1, p. 20.

BRASIL. Ministério da Agricultura, Pecuária e Abastecimento. Instrução Normativa no 27, de 05 de junho de 2006. Dispõe sobre fertilizantes, corretivos, inoculantes e biofertilizantes, para serem produzidos, importado ou comercializados, deverão atender aos limites estabelecidos nos Anexos I, II, III, IV e V desta Instrução Normativa no que se refere às concentrações máximas admitidas para agentes fitotóxicos, patogênicos ao homem, animais e plantas, metais pesados tóxicos, pragas e ervas daninhas. Diário Oficial da União, 09 de jun. 2006, Seção 1, p 15.

CASTRO, A. D. J. de; PINHEIRO, A.; GINORIS, Y. P. Aplicação do Método de Soluções de Problemas (PDCA), em um sistema de tratamento de efluentes de indústria frigorífica de aves. In: Revista Ambiente e Água - Na Interdisciplinary Journal of Applied Science, v. 6, n. 3, 2011.

CERRI, C. E. P.; OliveirA, E. C. A. de.; SARTORI, R. H.; GARCEZ, T. B. Compostagem. Universidade de São Paulo, Escola Superior de Agricultura Luiz de 
Quieroz, Programa de Pós-Graduação em Solos e Nutrição de Plantas, Piracicaba, SP, mai. 2008.

COSTA, M.S.S.M.; COSTA, L. A. de M.; DECARLI, L. D.; PELÁ, A.; SILVA, C. J. da; MATTER, U. F.; OLIBONE, D. Compostagem de Resíduos Sólidos de Frigorífico. Revista Brasileira de Engenharia Agrícola e Ambiental. Campina Grande, PB. 2008. Disponível em: < http://www.scielo.br/pdf/rbeaa/v13n1/v13n01a15.pdf>. Acesso em: 27 jun. 2013.

DORES-SILVA, P. R.; LANDGRAF, M. D.; REZENDE, M. O. de O. Processo de estabilização de resíduos orgânicos: vermicompostagem versus compostagem. In: Revista Química Nova, vol. 36, n. 5, p. 640-645, 2013.

GOMES, A. P. de O. Monitorização de uma instalação laboratorial de compostagem. Dissertação de Mestrado Integrado em Engenharia Química, Departamento de Engenharia Química da Faculdade de Ciências e Tecnologia da Universidade de Coimbra, Universidade de Coimbra, 2011.

GRAEPIN, C.; FOLLMANN, A. J.; SCHROEDER, J. K.; NEUHAUS, F.; RODRIGUES, A. C.; KEMERICH, P. D. da C. Compostagem como alternativa de destinação para o lodo flotado de abatedouro de frangos. In: Revista Monografias Ambientais - REMOA, vol. 13, n. 5, p. 4011-4018, dez. 2014. DOI:10.5902/22361308115161

HECK, K.; MARCO, E. G. de.; HAHN, A. B. B.; KLUGE, M.; SPILKI, F. R.; DER SAND, S. T. V. Temperatura de degradação de resíduos em processo de compostagem e qualidade microbiológica do composto final. In: Revista Brasileira de Engenharia Agrícola e Ambiental, vol. 17, n. 1, p. 54-59, 2013.

JÚNIOR, M. A. P. O.; ORRICO, A. C. A.; JÚNIOR, J. de. L. Compostagem dos resíduos da produção avícola: cama de frangos e carcaças de aves. In: Revista Engenharia Agrícola, v. 30, n. 3, p. 538-545, mai./jun. 2010, Jaboticabal, SP.

LEITÃO, V. de P. M.; MOTA, F. S. B.; SILVA, J. C. da C. e; LIMA, C. R. G. de; SILVA, L. A. da. Análise da relação carbono/nitrogênio na compostagem de folhagens e esterco. In: 26ํㅡ Congresso Brasileiro de Engenharia Sanitária e Ambiental, CD-ROM, set. 2011.

OLIVEIRA, A. M. G.; AQUINO, A. M. de; NETO, M. T. de C. Compostagem Caseira de Lixo Orgânico Doméstico. Circular Técnica 76, Ministério da Agricultura, Pecuária e Abastecimento, 1ํㅡㄹ. ed., Embrapa, Cruz das Alamas, BA, dez. 2005.

PAIVA, E. R.; MATOS, A. T. de; AZEVEDO, M. A.; BARROS, R. T. P. de; COSTA, T. D. R. Avaliação da compostagem de carcaças de frango pelos métodos da composteira e de leiras estáticas aeradas. In: Revista Engenharia Agrícola, Jaboticabal, vol. 32, n. 5, p. 961-970, set./out. 2012.

RIBEIRO, R. M.; AMENDOLA, E. C.; ANDRADE, V. H. F.; MIRANDA, B. P. Utilização de cinza vegetal para calagem e correção de solos - um estudo de 
caso para a região metropolitana de Curitiba (RMC). In: Revista Agrarian Academy, Centro Científico Conhecer, Goiânia, vol. 2, n. 3, p. 115, 2015.

SANTOS, J. L. D. dos. Caracterização físico-química e biológica em diferentes laboratórios de produtos obtidos a partir da compostagem de resíduos orgânicos biodegradáveis. 2007. 144 p. Dissertação (Mestrado em Ecologia Aplicada) - Universidade do Porto, Porto, Portugal, 2007.

SILVA, M. E. F. Co-compostagem de resíduos avícolas e de resíduos florestais - um estudo na região de Viseu. 2003. 145 p. Dissertação (Mestrado em Engenharia do Ambiente) - Universidade do Porto, Porto, Portugal, 2003.

SUNADA, N. da S.; ORRICO, A. C. A.; JUNIOR, M. A. P. O.; CENTURION, S. R.; OLIVEIRA, A. B. de M.; FERNANDES, A. R. M.; JUNIOR, J. de L.; SENO, L de O. Compostagem de resíduos sólido de abatedouro avícola. In: Revista Rural, Santa Maria, v. 45, n. 1, p. 178-183, jan., 2015.

VALENTE, B.S.; XAVIER, E. G.; MORSELLI, T. B. G. A.; JAHNKE, D. S.; JUNIOR, B. de S. B.; CABRERA, B. R.; MORAES, P. de O.; LOPES, D. C. N. Fatores que Afetam o Desenvolvimento da Compostagem de Resíduos. In: Arché. Zootc, no 58, $\quad$ p. $\quad 59-85, \quad 2009 . \quad$ Disponível em: <http://www.uco.es/organiza/servicios/publica/az/php/img/web/07_18_48_1395REVI SIONFatoresValente1.pdf>. Acesso em: 27 jun. 2013.

WARTCHOW, D.; GEWEHR, A. G.; SILVA, J. S. da. A importância ambiental e econômica da compostagem - Estudo de caso: município de ljuí/RS. In: 26o Congresso Brasileiro de Engenharia Sanitária e Ambiental, CD-ROM, set. 2011. 